\title{
THE EFFECT OF MULTIMEDIA ON ENHANCING MATHEMATICAL PROBLEM-SOLVING SKILLS AMONG SEVENTH GRADE STUDENTS IN NORTH EASTERN PROVINCE, SULTANATE OF OMAN

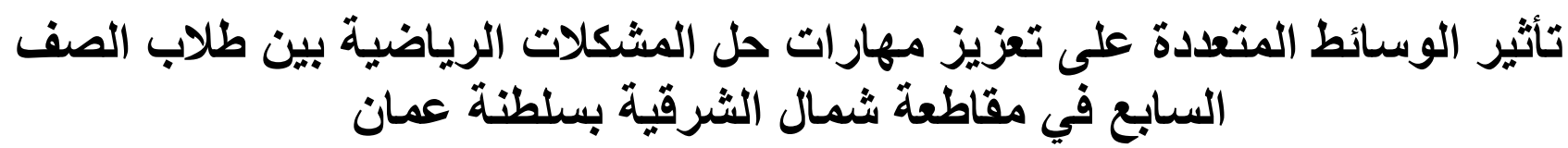

\author{
إسحاق بن حميل بن سعيد الجابري \\ Isehaq Humaid Said Humaid Al Jabri ${ }^{1 *}$, and Muhammad Sabri Sahrir ${ }^{2}$ \\ ${ }^{1} \mathrm{Ph}$.D. Candidate (Education) at the Faculty of Education, International Islamic University Malaysia \\ (IIUM); aass123gg@gmail.com \\ ${ }^{2}$ Prof. Dr. at the Faculty of Education, International Islamic University Malaysia (IIUM); \\ muhdsabri@iium.edu.my \\ ${ }^{*}$ Corresponding Author
}

\begin{abstract}
This quantitative, analytical study discusses the impact of multimedia on enhancing mathematical problemsolving skills among seventh graders in the Northeast District. Where the problem arose in that research and studies indicated the low level of performance of seventh-graders in solving mathematical problems, and that the teaching method used is dominated by speech and instruction on the part of the teacher, and memorization and memorization on the part of the student, without interest in improving the level of his higher thinking capabilities, including the ability to Mathematical problem solving. Therefore, the study aims to discuss the impact of multimedia on enhancing mathematical problem-solving skills among seventh graders, and to know the suggestions of teachers and specialists in developing the multimedia program. The researcher used the descriptive approach and the semi-experimental approach to a sample of students of (153) students for mathematics. The study tools included; the achievement test in the skills of solving the pre and post mathematical problems of the control and experimental group, as well as a motivational measure in mathematics. The sample was divided into a control group (77) students, and an experimental group (76) students. The results showed that there was a statistically significant difference at the significance level $(0.05)$ between the mean scores of the pre and post measurements of the experimental group students, which were studied according to the multimedia program on the mathematical problem-solving test for mathematics course. And the presence of a statistically significant difference at the significance level $(0.05)$ between the mean scores of the experimental group students and the students of the control group on the problem-solving test.
\end{abstract}

Keywords: multimedia, problem solving, mathematics.

\section{الملخص}

تناقش هذه الدراسة الكمية التحليلية أثر الوسائط المتعددة في تعزيز مهارات حل المشكلات الرياضية بين

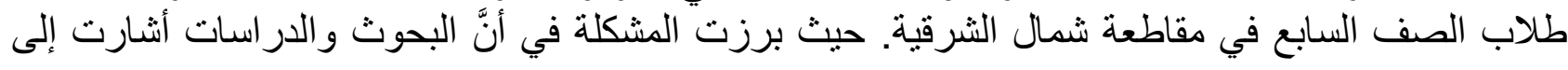


تدني مستوى أداء طلاب الصف السابع في حل المشكلات الرياضية، وأنَّ طريقة التدريس المستخدمة؛ يغلب

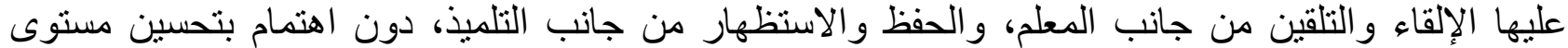

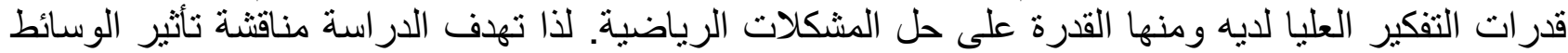
المتعددة على تعزيز مهار ات حل المشكلات الرياضية بين طلاب الصفات الصف السابع، ومعرفة مقترحات المعلمين

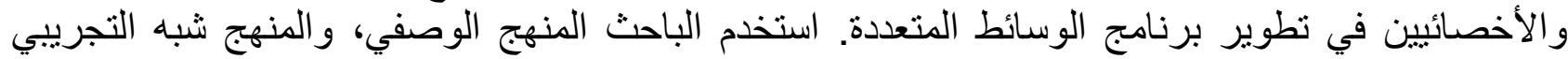

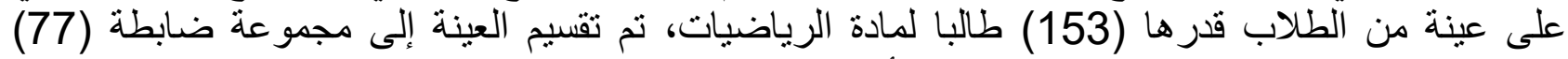

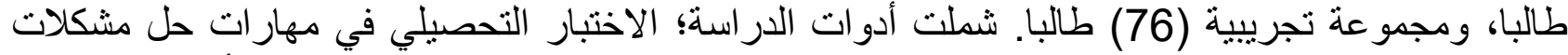

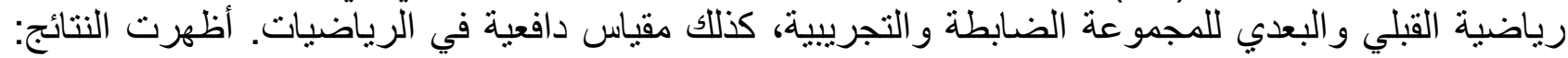

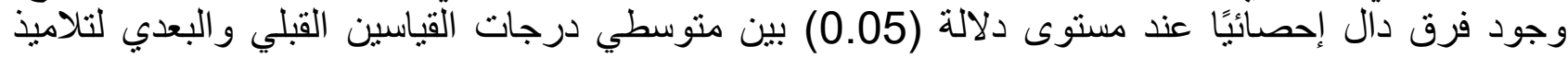

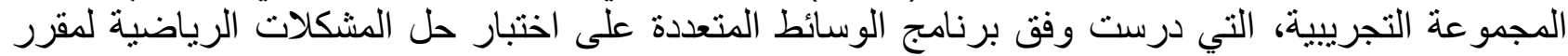

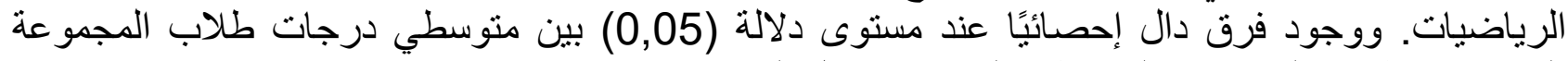
التجريبية وطلاب المجموعة الضابطة على اختبار حل المشكلات.

كلمات مفتاحية: الوسائط المتعددة، حل المشكلات، الرياضيات.

\section{المقدمة:}

يمكن القول إن مجالات التطبيق للرياضيات المعاصرة تتسع آفاقها وتزداد بما بحقق لها قيادة حقيقية في

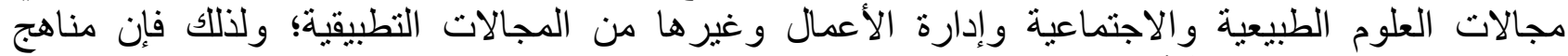

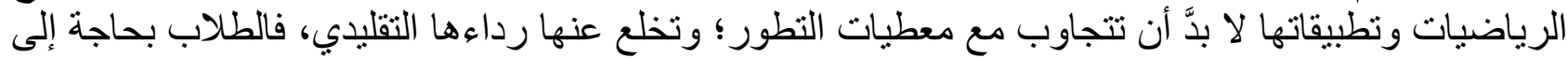
رياضيات أكثر نفعية في مسالكهم المعيشية، ويسهم تعلمها في إعدادهم لمواجهة تحديات المئية المستقبل (عبيد،

.(1998

و على الرغم من جهود القائمين علي تطوير المناهج بوزارة التعليم في سلطنة عمان لتطوير مناهج الرياضيات

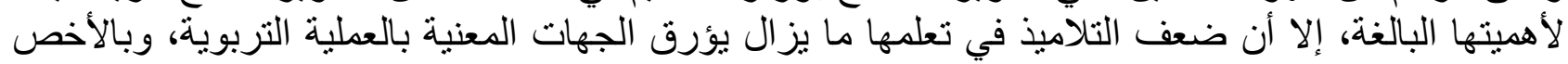

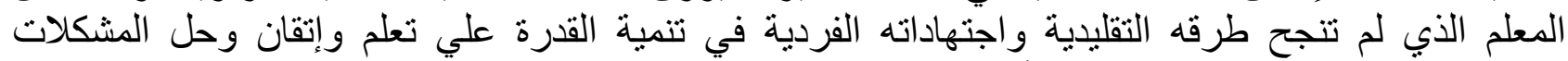

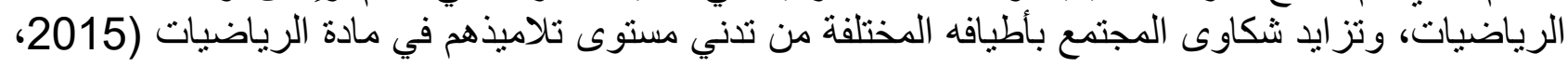

(TIMSS

إنَّ تدريس الرياضيات الحديثة يقوم أساسا على حل المشكلات الرياضية، التي لها أثر كبير في تتمية مهار ات

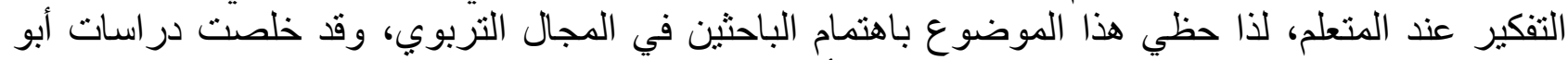

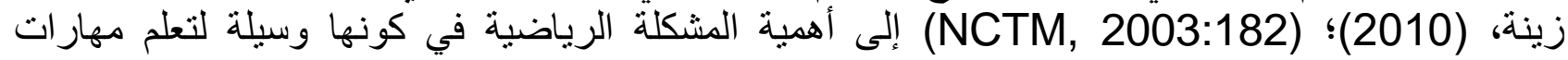
ومعارف رياضية وتعزز فهم العلاقات الرياضية، و إنها وسيلة للتدريب على المهارات الحسابية و اكتسابها أيضا. كذللك يتم عن طريق حل المشكلات الرياضية؛ توظيف القو انين و التعميمات الرياضية في في مو اقف جديدة. ويرى النجدي، (2015: 155) أننا عند استشراف المستقبل في القرن الحادي والعشرين، نحتاج مراجعة

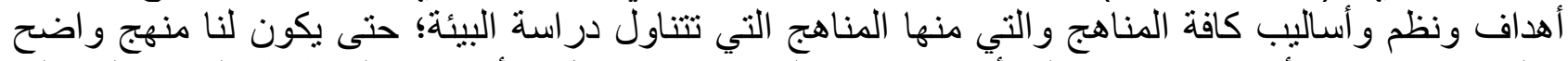

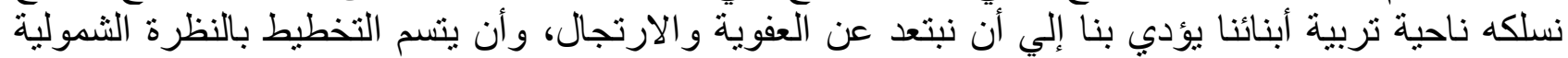

المستقبلية.

تعرف عياد (2008: 9) الوسائط المتعددة بأنها "استخدام أكثر من نوع من الوسائل سواء كانت الوسائل

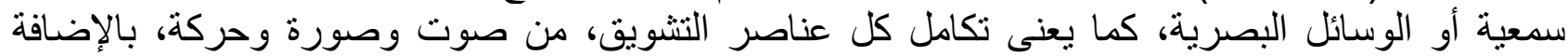

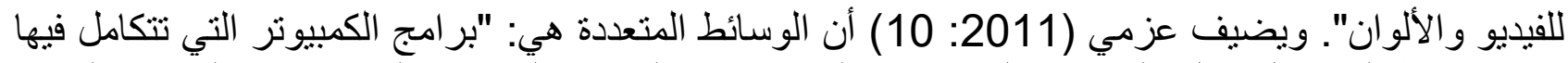

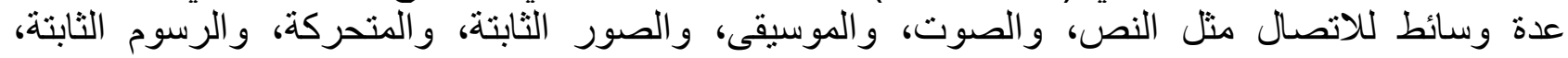


و المتحركة، والتي يتعامل معها المستخدم بشكل تفاعلي".

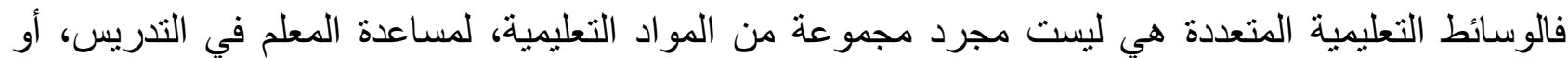

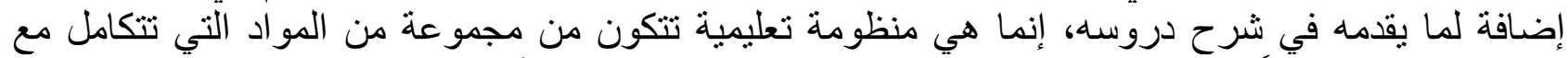

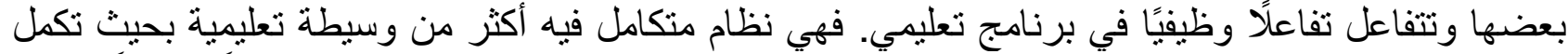

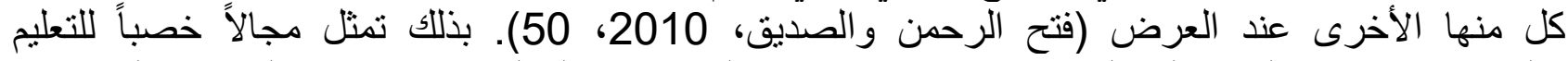

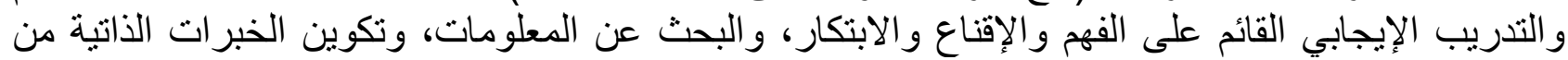
خلال العملية التعليمية وربط التعليم بالتطبيق في الحياة التئية والعملية.

عرَّفت المالحي، (2006: 76) حل المشكلات الرياضية (Skills Mathematical Problems) بأنها: "ذلك النشاط الذي يقوم به التلميذ عند محاولته لربط العلاقة بين المعلومات السابقة

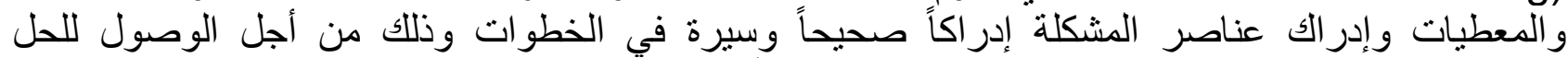

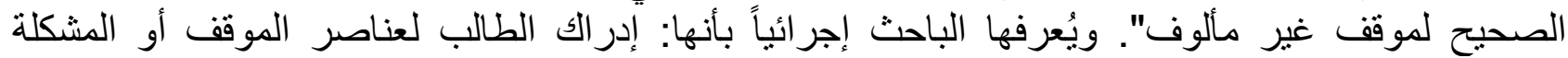

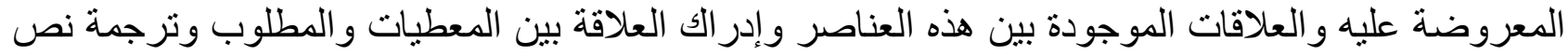

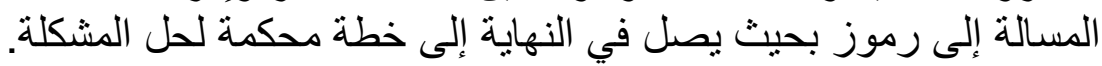

مشكلة الار اسة:

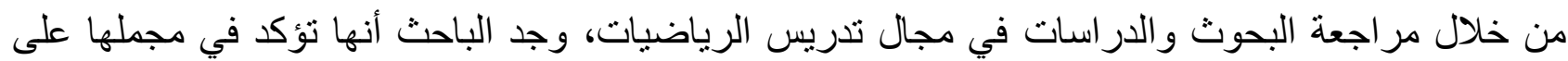
تدني مستوى أداء طلاب الصف السفابع في في حل المشكلات الرياضية في مقاطعة شمال الثرقية بسلطنة عمان،

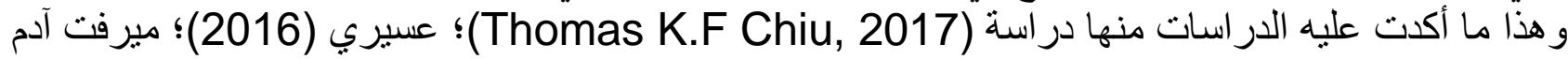

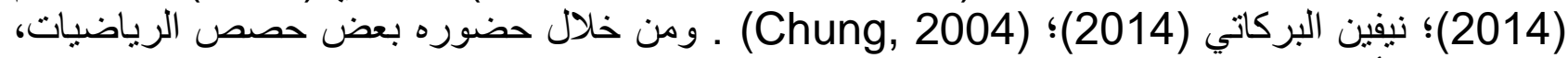

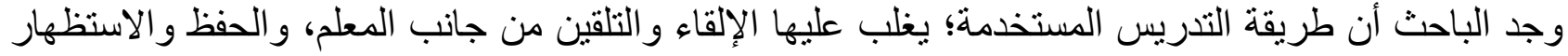
من جانب التلميذ، دون اهتمام بتحسين مستوى قدرات التفكير العليا لديه ومنها القدرة على التى حلى حل المشكلات الرياضية. ورذا ما ذكر أيضاً في دراسة خليفة (2008) حين أثنار إلى الأساليب التقليدية في تدريس التئ الرياضيات.

و من أهم الأسباب التي دفعت الباحث للبحث في هذه المشكلة؛ هو تدني مستوى الطلاب في اختبارات تميس

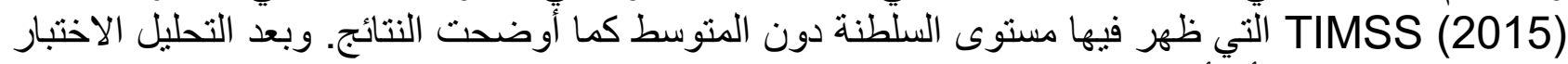
من قبل الوزارة ظهر أن أضعف الجوانب تمثل في تدني مسائل حل المشكلات. وللتأكيد على المشكلة، تم مراجعة نتائج طلاب الصف السابع للعام الدراسي (2018 - 2019) لدى قسم

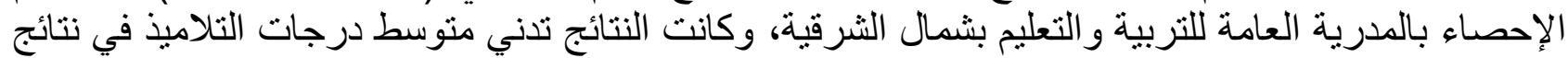

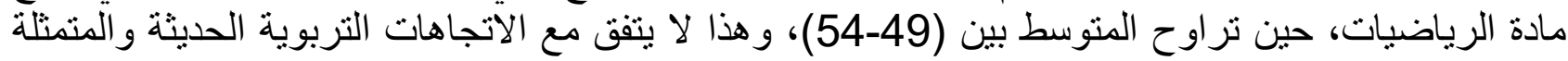
في الوصول بمستوى المنتوجات التعليمية إلى حد الإنى التقان. أهداف الاراسة:

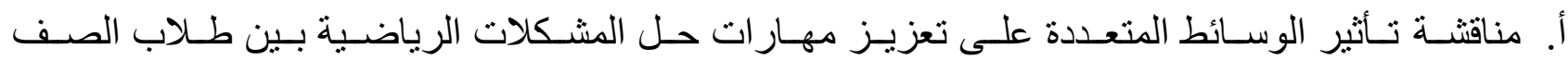

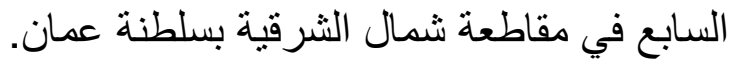

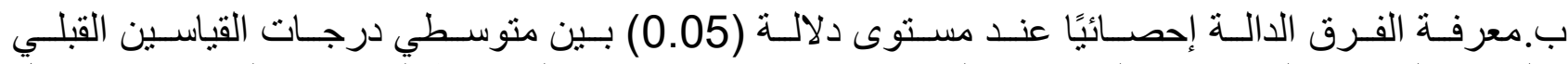

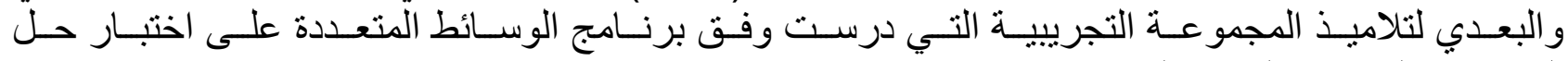
المشكلات الرياضية لمقرر الرياضيات.

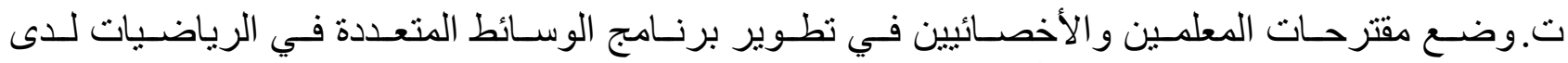
طلاب الصف السابع في مقاطعة شمال الثرقية بسلطنة عمان. 


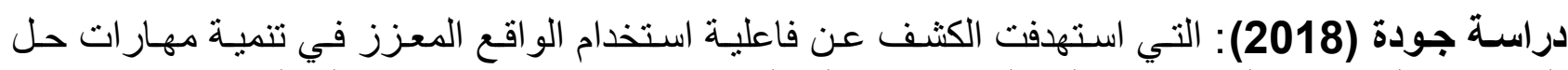

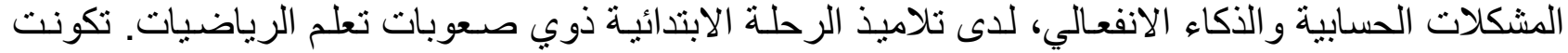

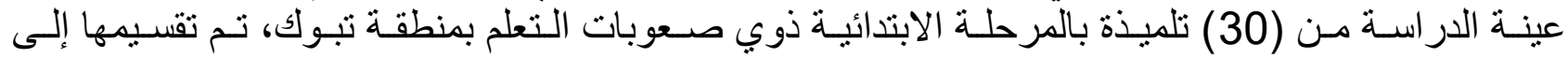

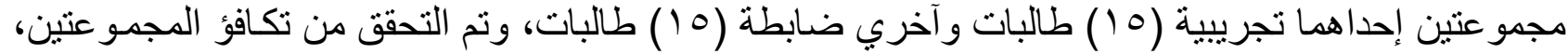

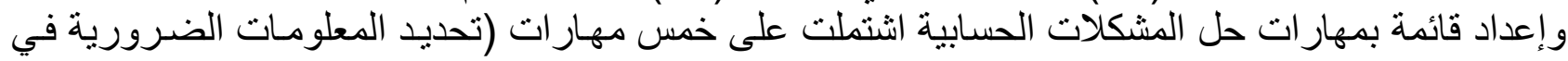

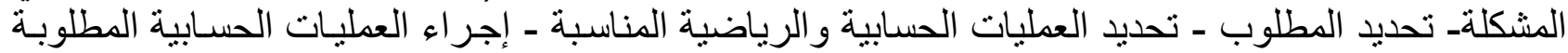

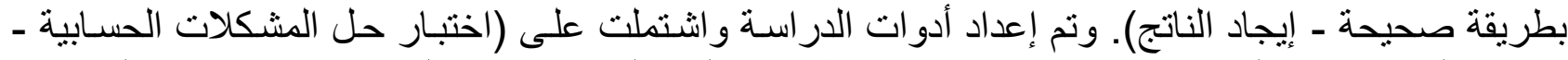

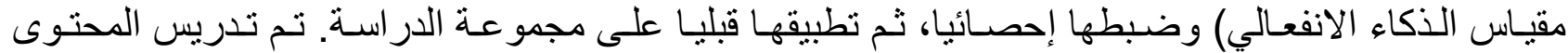

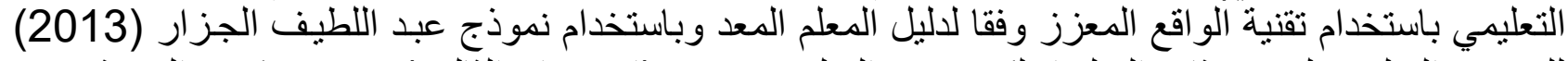

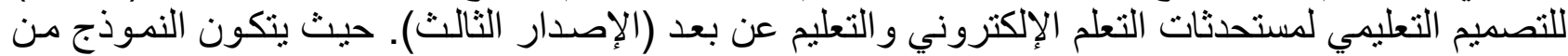

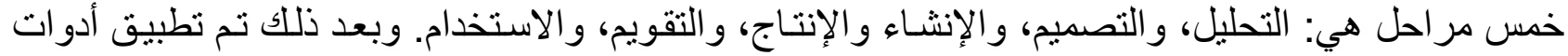

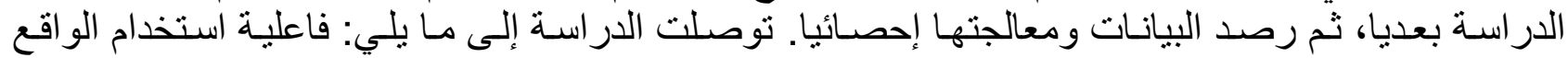

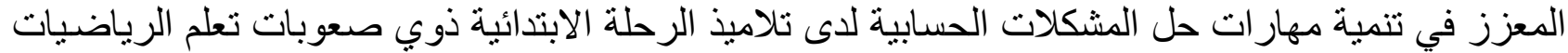

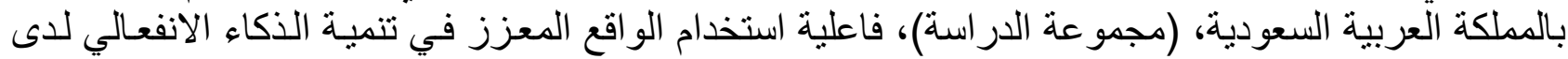

تلاميذ الرحلة الابتدائية ذوي صعوبات تعلم الرياضيات بالمملكة العربية السعودية.

دراسة بيومي والجندي (2017): استهدفت استقصاء مدى فاعلية استر اتيجية عظم السمكة في تنمية التحصيل

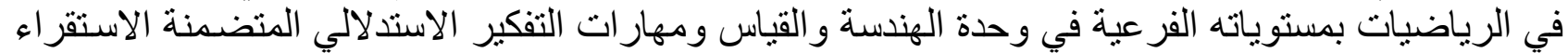

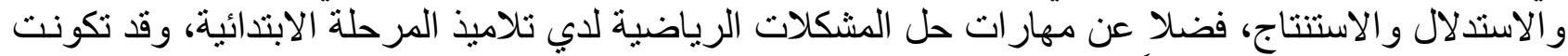

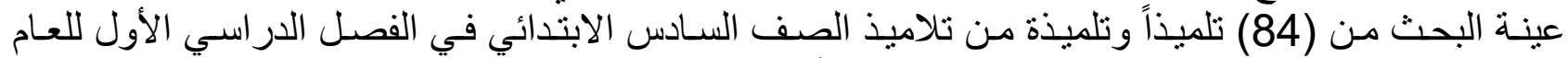

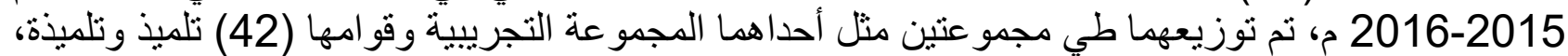
و الأخرى المجموعة الضابطة وقو امها (42015) تلميذا وتلميذة، وقد استخدم الباحثنان منهج البحث شئ شبه التجريبي

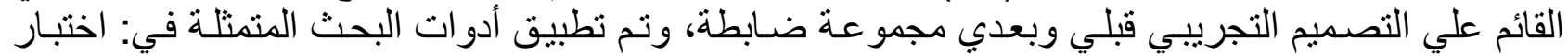

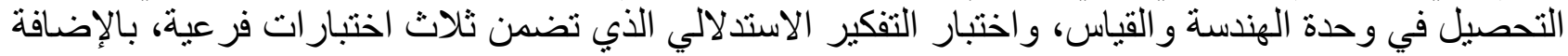

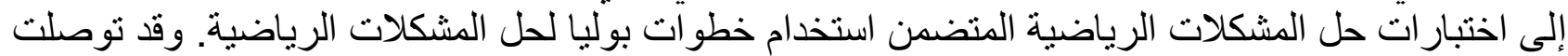

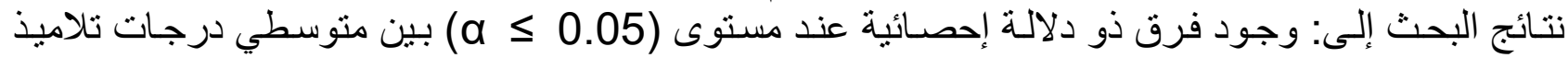

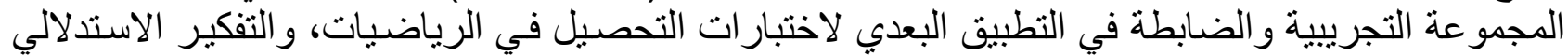

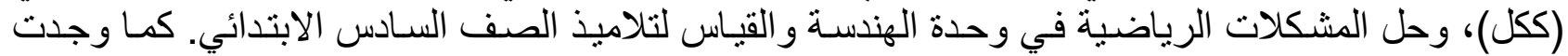
علاقة ارتباطية دالة موجبة بين درجات تلاميذ المجموعة التجريبية بين متغير ات البحث (التحصيل، التفكير

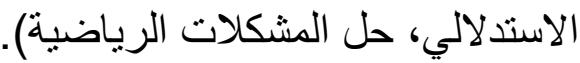

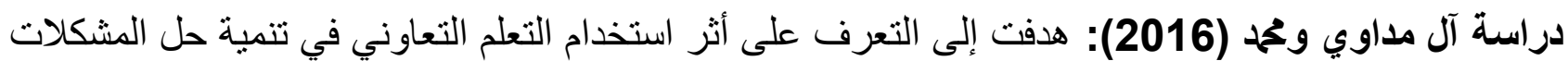

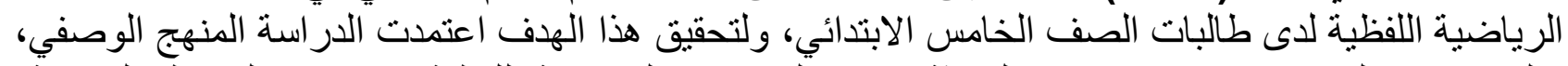
و المنهج شبه التجريبي، وقد استخدمت الباحثة اختبار المشكلات الرياضية اللفظية في وحدة (المحيط، المساحةً،

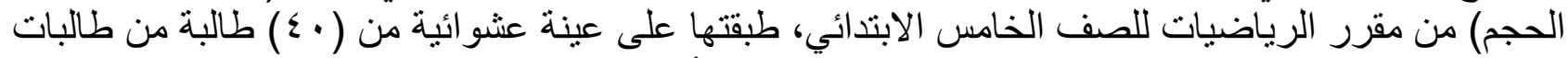
الصف الخامس الابتدائي بإحدى المدارس الابتدائية في مدينة أبها التابعة لإدارة التربية وانية والتعليم بمنطقة عسير،

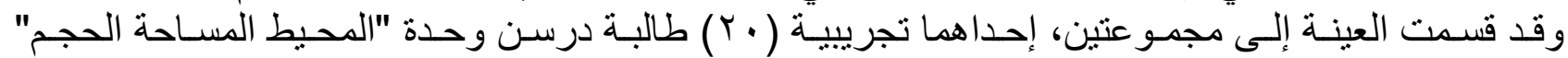

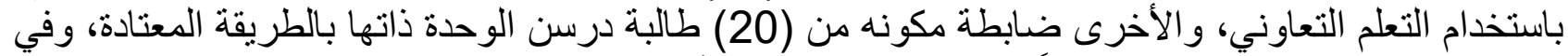

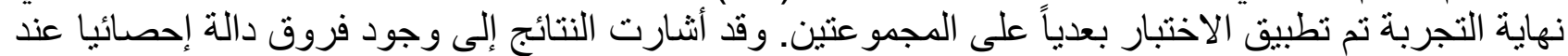
مستوى (a=0.05) بين متوسط درجات طالبات المجمو عتين التجريبية والضابطة في التطبيق البعدي لاختبار

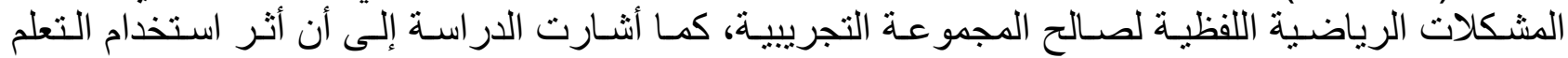
التعاوني في تنمية حل المشكلات الرياضية اللفظية كان عاليًا.

دراسة الشيخي (2016): التي هدفت إلى استقصساء مستوى قدرة طلاب الصف الثالث الثانوي (تخصص طبيعي) بمحافظة الأحساء على حل مشكلات رياضية في الأعداد و الهندسـة مختارة من اختبـار ات المسـابقات 


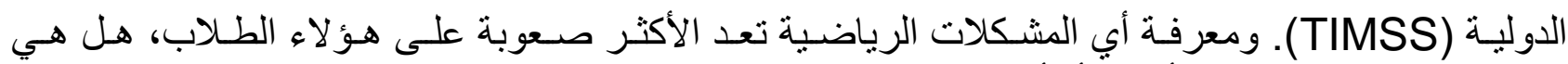

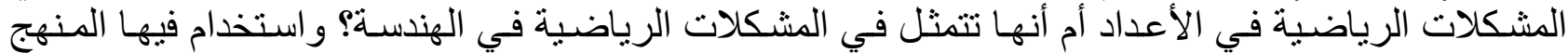

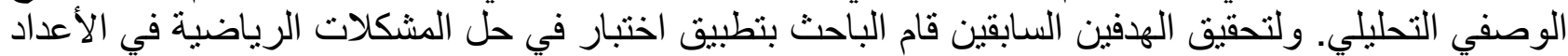

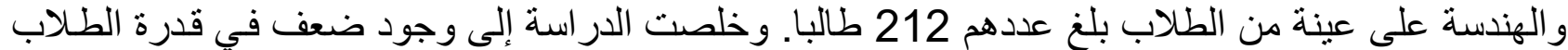

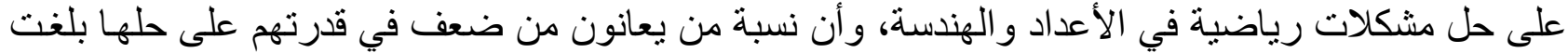

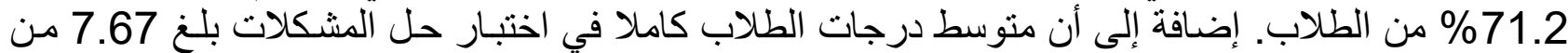

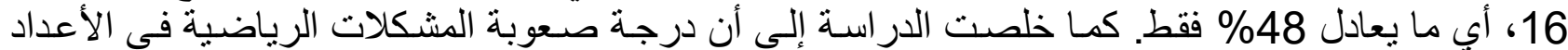

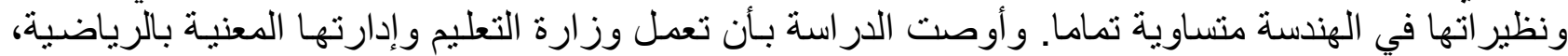

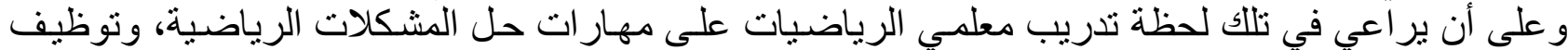

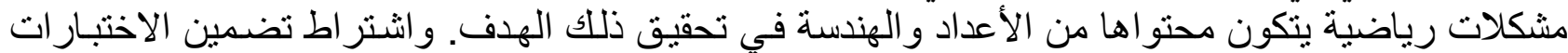
التي تقدم في الرياضيات لأسئلة من مستوى التطبيق فأعلى. وتدريب الطلاب على اختبار ات المسابقات الدولية منذ مر احل مبكرة من التعليم العام.

دراسـة الراجح (2015): استهدفت الكثف عن مستوى طالبـات كليـة التربيـة في حل المشكلات الرياضية.

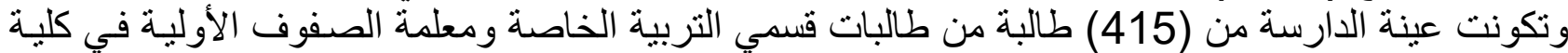
التربية. و استخدمت الدر اسة المنهج الوصفي، وتم إعداد اختبار يقيس مهارة حل المشكلات الرياضية وتوصلت

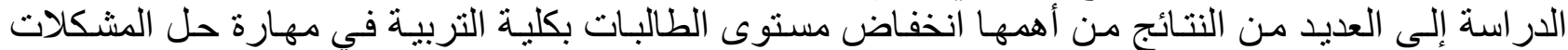

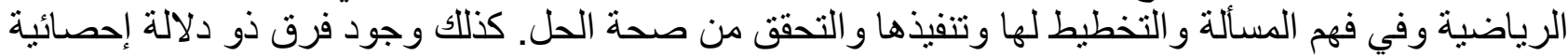
بين متوسطي درجات طالبـات تخصص معلمـة صف و التربيـة الخاصـة في اختبـار حل المشكلات الرياضية لصالح معلمة الصف. ورن لا يوجد فرق ذو دلالة إحصائية بين متوسطي درجات طالبات العلمي و الأدبي بالمرحلة الثانوية في مهارة حل المشكلات الرياضية.

منهج الاراسة:

استخدم الباحث المنهج الوصفي: الذي يعنى بوصف ما هو كائن من الظاهرة وتفسيره، وجمع المعلومات وتصنيفها وتحليل الأدبيات و البحوث و الدر اسات السابقة ذات الصلة بموضوع البن البحث.

كما استخدم المنهج شبه التجريبي؛ لمعرفة أثز المتغير المستقل وهو برنامج وسائط متعددة على المتغيرات التابعة وهي تعزيز مهارات حل المشكلات في الرياضيات ـ تعزيز الدافعية للإنجاز في الرياضيات لدى لئي طلاب الصف السابع بمقاطعة شمال الثرقية.

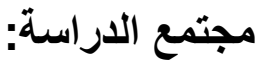

يتكون من جميع تلاميذ الصف السابع الأساسي في محافظة شمال الثرقية، وقد بلغ عداد التلاميذ (2024) تلميذا، حسب بيانات قسم الإحصاء بالمديرية الَعامة للتربية و التعليم بشمال الثرقية (2019)، موزعين على عدد من المدن و القرى بالمحافظة.

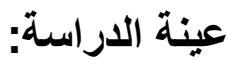

تم تحديد عينة الدر اسة بطريقة قصدية من طلاب الصف السابع أساسي، في (3) مدارس موزعة في في عدة مدن

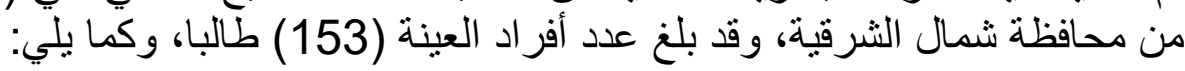

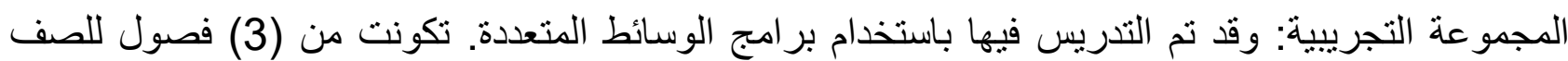

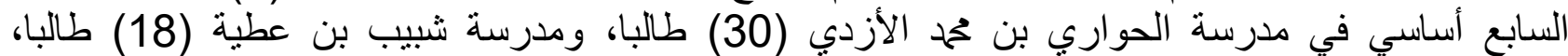
ومدرسة الخير ات (28) طالباً،

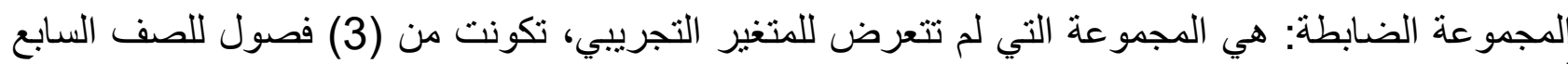

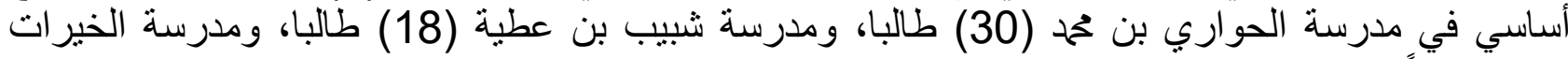
(29)" طالباً، وقد تم التدريس فيه بالتعلم التقليدي. 
ضبط متغيرات الدراسة:

للتأكد من تكافؤ المجمو عتين (التجريبية و الضابطة)؛ قام الباحث بضبط عدد من المتغير ات المرتبطة بخصائص

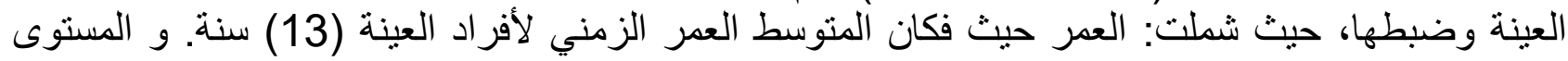

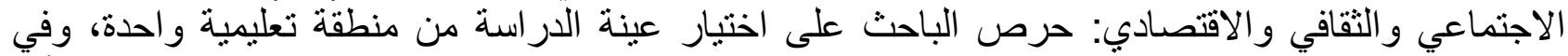

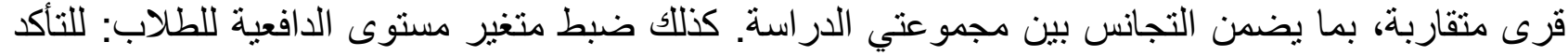

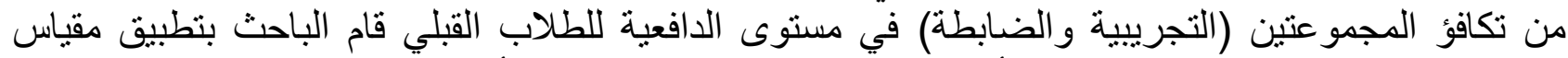

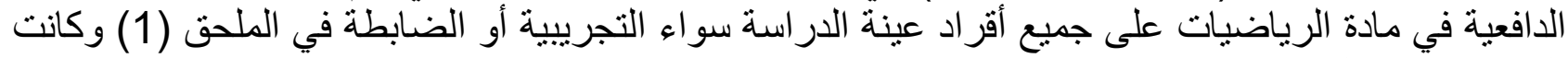

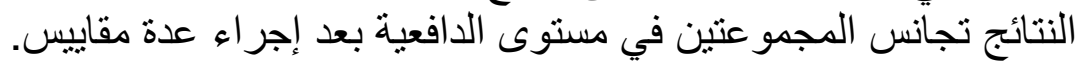
ثم جرى ضبط متغير المستوى العلمي وتجانس المجموعتين: للتأكد من تكافؤ المجموعتين (التجريبية و الضابطة) في المستوى التحصيلي و العلمي القبلي قام الباحث بمر اجعة نتائج الطلاب في مادة الرياضنات لمدة

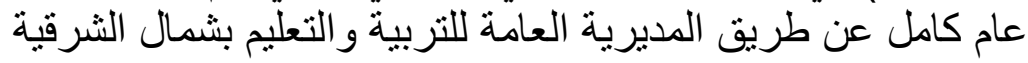

\section{إعداد وبناء الوحدة المحوسبة المقترحة:}

جرى بناء الوحدة المحوسبة المقترحة (وحدة المساحة والمحيط) للصف السابع، لمعرفة فاعلية دراسة هذه المداء

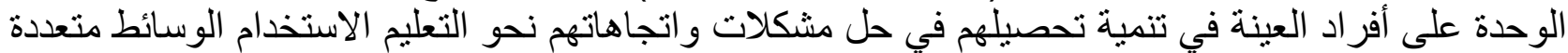
ومقارنة ذلك مع الطلاب الذين يدرسون الوحدة ذاتها بالطريقة التقليدية. تم تطبيق الدرس وفق نموذج حمد خميس (2007): الذي يعد من النماذج الثاملة لعمليات التصميم و التطوير

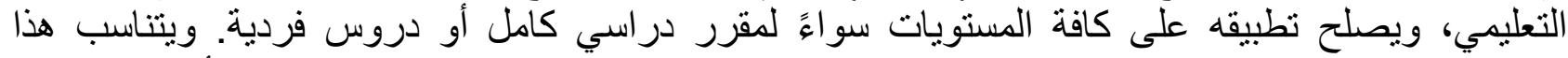

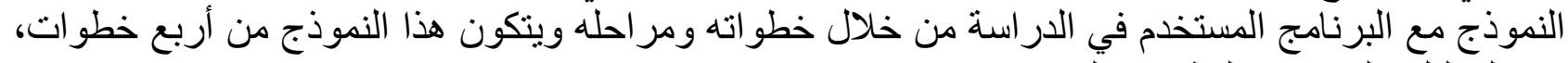

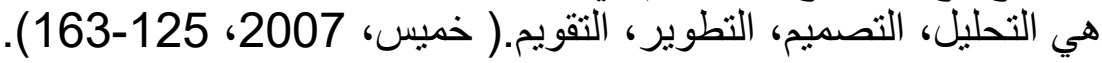
أدوات الاراسة:

من أجل تحقيق أهداف الدراسة في الكثف عن أثر الوسائط المتعددة في تعزيز مهارات حل المشكلات

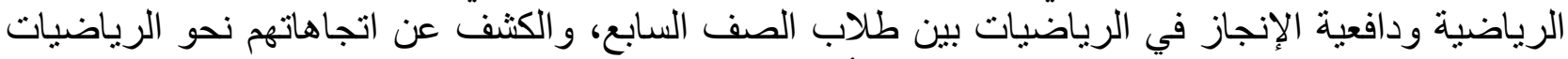

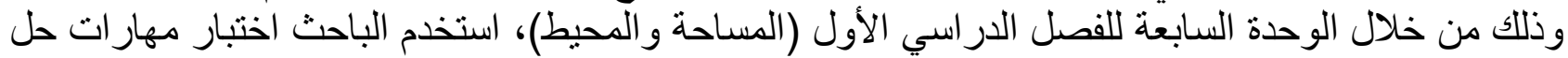

المشكلات الرياضية.

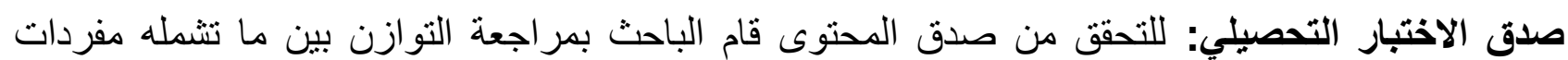

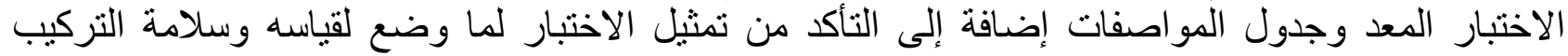
اللغوي لمفرداته بحيث تعطي الدلالات المطلوبة. ثم قام الباحث بحساب معامل التمييز لكل سؤال في الإن الاختبار

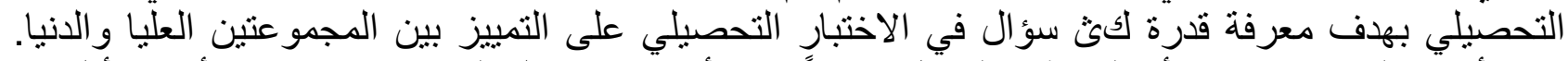

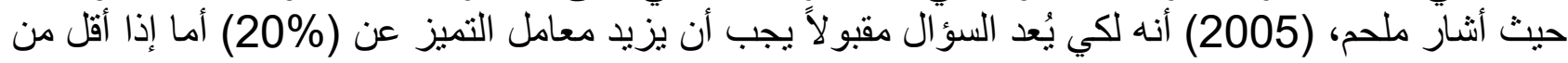
ذلك فيجب تعديله.

\section{الاختبار التحصيلي في صورته التهائية:}

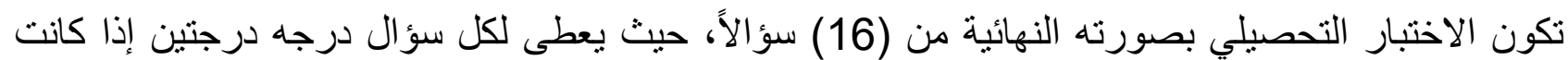

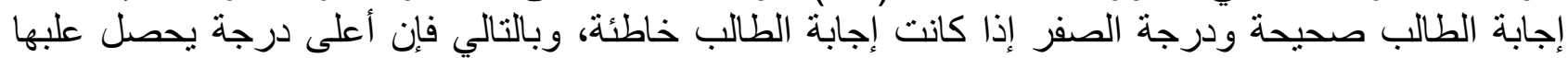

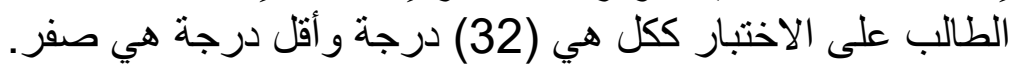
الأساليب الإحصائية المستخدمة:

لحساب وجود فرق دال إحصائيًا عند مستوى دلالة (0.05) بين منوسطي درجات القياسين القبلي و البعدي

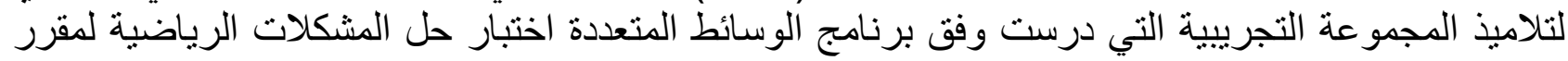


- التكر ارات والأوزان النسبية واختبار حسن المطابقة (معادلة كا2).

Paired - Samples t-Test.اختبار ات (t.Test)

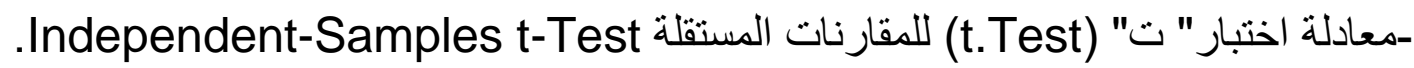

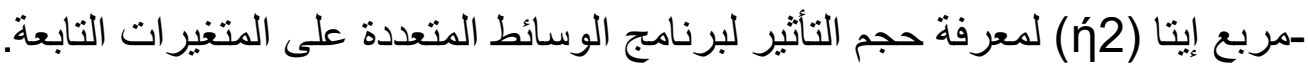
نتائج الاراسة: عرض النتائج المتعلقة بالسؤال الأول وتفسيرها: نص هذا السؤال على الاتي: ما مدى تأثير الوسائط المتعددة على تعزيز مهار اتلعات حل المشكلات الرياضية بين طلاب الصف السابع في مقاطعة شمال الثرقية بسلطنة عمان؟

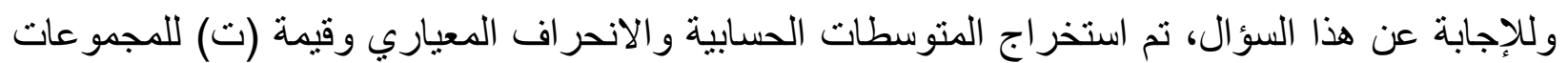

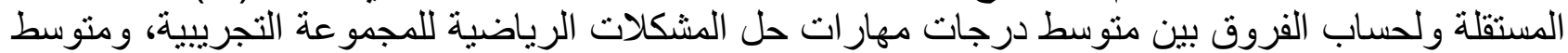

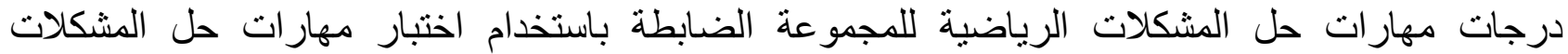
الرياضية في مادة الرياضيات، وجدول الآتي يوضح ذلكات الكئ.

جدول (1) المتوسطات الحسابية والانحر اف المعياري وقيمة (ت) لدرجات مهار الترات التربات حل المشكلات الرياضية للمجمو عة التجريبية والضابطة في مادة الرياضيات لاتيات

\begin{tabular}{|c|r|r|r|r|r|c|}
\hline التجمئ| \\
\hline
\end{tabular}

يلاحظ من جدول (1) وجود فروق ذات دلالة إحصائية عند مستوى الدلالة (0.05) بين درجات الرات الكاتيات

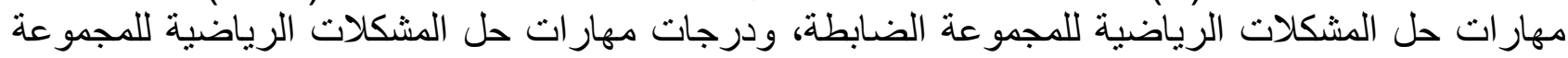

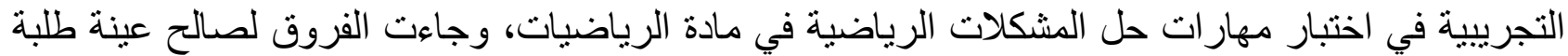

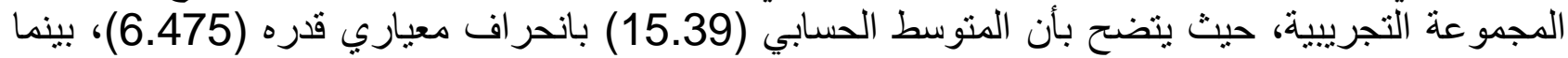

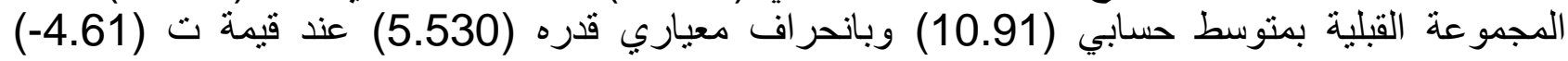

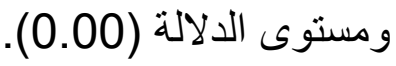

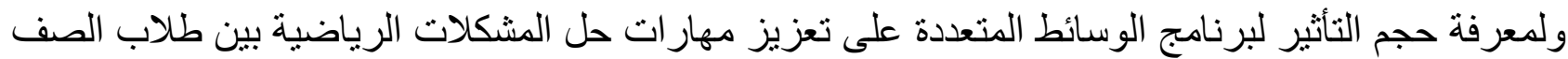

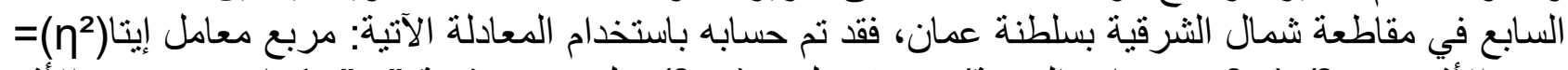

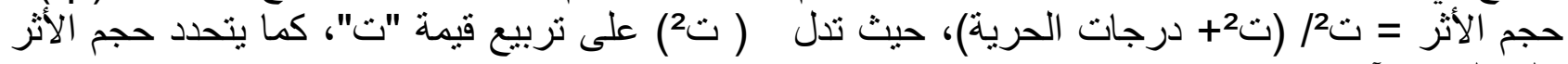

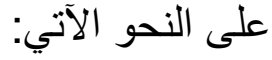

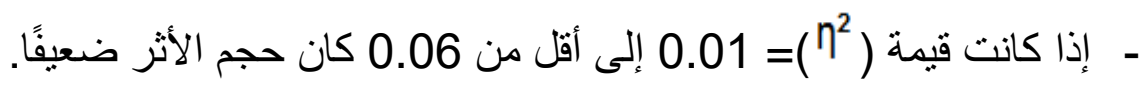

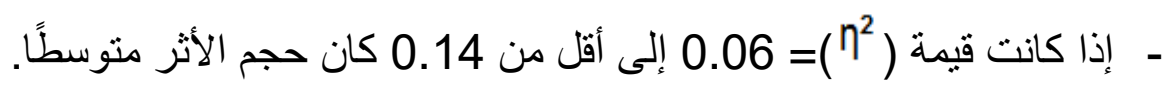

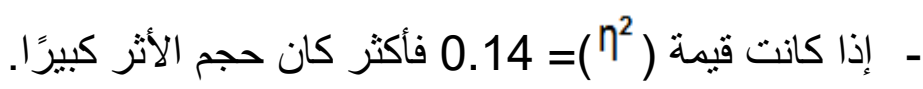
ويوضح جدول (2) الآتي نتائج حساب حجم الأثر جدول (2) قيمة (n2) ومقدار حجم أثر برنامج الوسائط المتعددة على تعزيز مهار ات حل المشكلات الرياضية 
IJASOS- International E-Journal of Advances in Social Sciences, Vol. VI, Issue 17, August 2020

\begin{tabular}{|c|c|c|c|c|c|}
\hline مقدار حجم الأثر & قيمة (n) & الحرية & قيمة "ت" & المتغير التابع & المستقيل \\
\hline متوسط & 0.123 & 151 & -4.610 & المشكلات الرياضية حل & الوتعددة \\
\hline
\end{tabular}

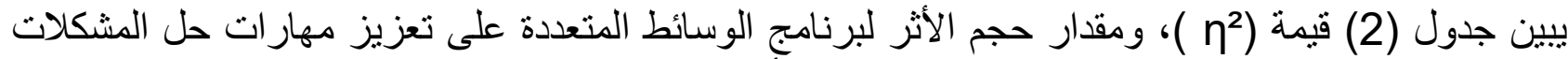

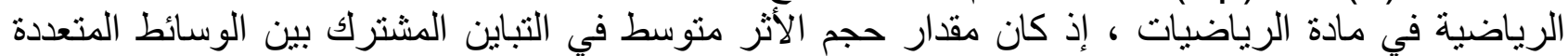

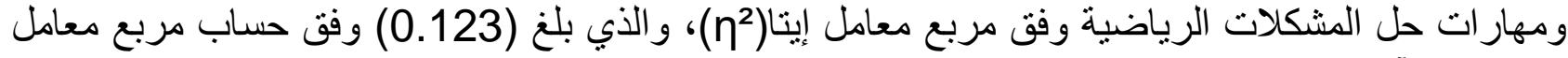

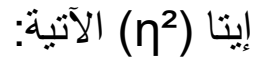

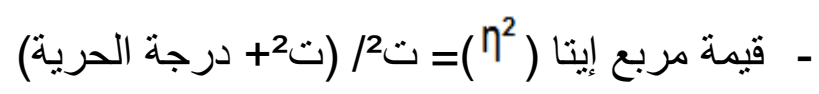$$
\text { - }
$$

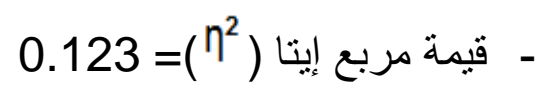

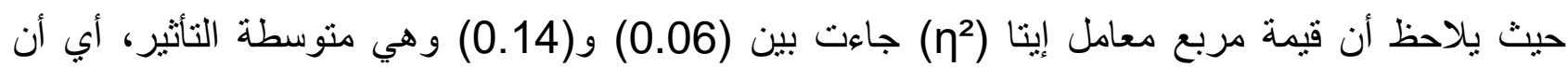

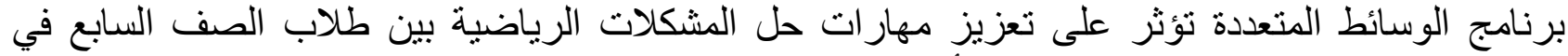

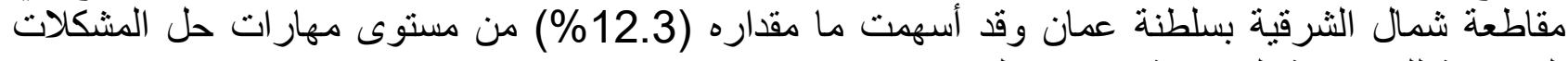
الرياضية للمجمو عة التجريبية في مادة الرياضيات.

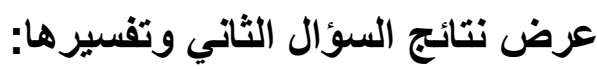

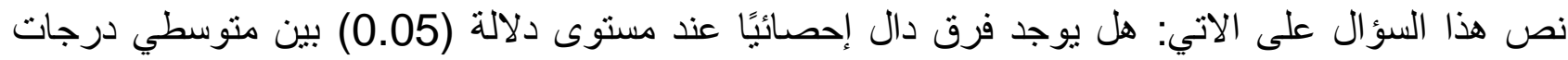

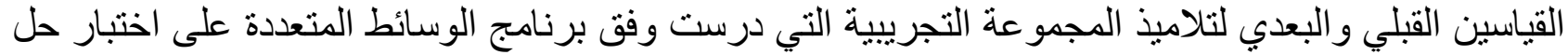

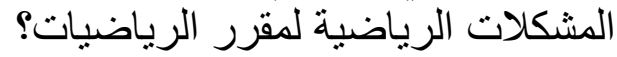

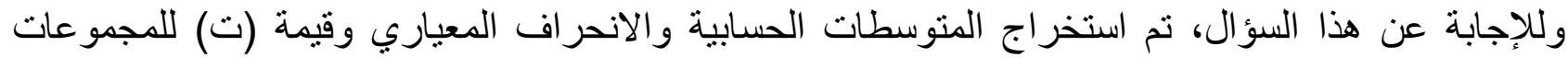

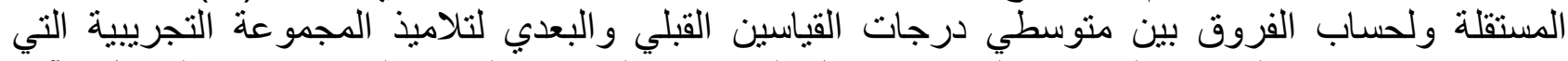

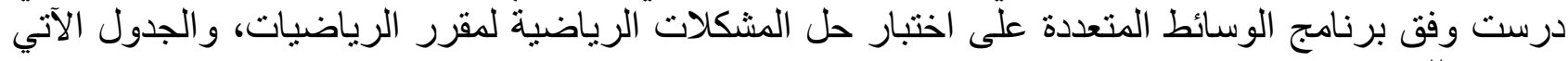
يوضح ذللك. جدول (3) المتوسطات الحسابية و الانحر اف المعياري وقيمة (ت) بين متوسطي درجات القيات القياسين القبلي

\begin{tabular}{|c|c|c|c|c|c|c|}
\hline مستوى الدلاية & قيمة ت & درجات الحرية & المعياري & المتوسطات & العدد (ن) & المجموعة \\
\hline \multirow{2}{*}{0.00} & \multirow{2}{*}{-8.106} & \multirow{2}{*}{152} & 4.153 & 8.30 & 78 & القبلية \\
\hline & & & 6.475 & 15.39 & 76 & البعدية \\
\hline
\end{tabular}
و البعدي في مقياس اختبار حل المشكلات الرياضية لتلاميذ المجمو عة التجريبية لئية في مادة الرياضيات

يلاحظ من جدول (3) وجود فروق ذات دلالة إحصائية عند مستوى الدلالة (0.05) بين منوسطي درجات

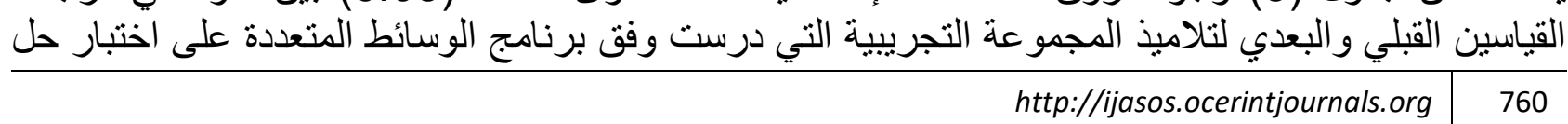


المشكلات الرياضية لمقرر الرياضيات، وجاءت الفروق لصالح عينة طلبة المجموعة البعدية، حيث يتضح بأن

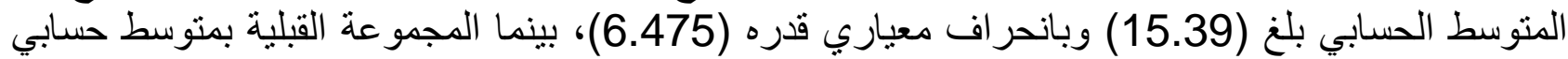
بلغ (8.30) وبانحر اف معياري قدره (153) (153) عند قيمة ت (8.106-) ومستوى الدلالة (0.00) (0.47).

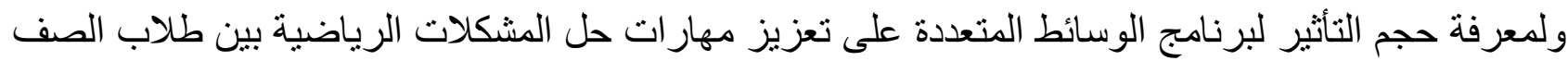

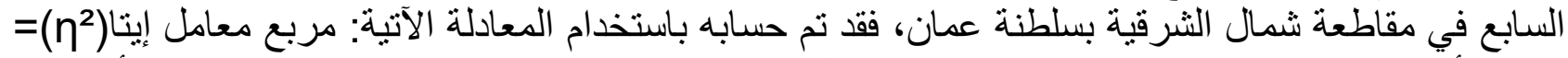

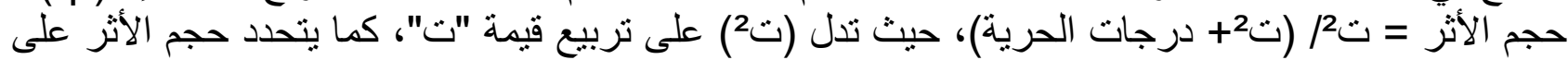
النحو الآتي: - إذا كانت قيمة ( $0.01=01$ إلى أقل من 0.06 كان حجم الأثر ضعيفًا. - إذا كانت قيمة ( - إذا كانت قيمة ( $0.14=0$. يوضح الجدول الآتي نتائج حساب حجم الأثر: جدول (4) قيمة (n2) ومقدار حجم أثز برنامج الوسائط المتعددة على تعزيز مهار ات حل المشكلات الرياضية للمجموعة التجريبية

\begin{tabular}{|c|c|c|c|c|c|}
\hline مقدار حجم الأثر & قيمة (n) & الحرية & قيمة "ت" & المتغير التابع & المستقليز \\
\hline كبير & 0.302 & 152 & -8.106 & المشكلات الرياضية حل & الوستعدة المئط \\
\hline
\end{tabular}

يبين جدول (4) قيمة (和)، ومقدار حجم الأثر لبرنامج الوسائط المتعددة على تعزيز مهار ات حل المشكلات

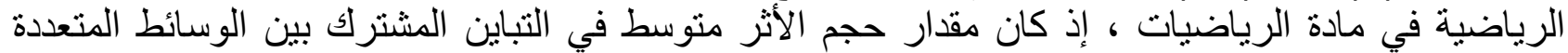

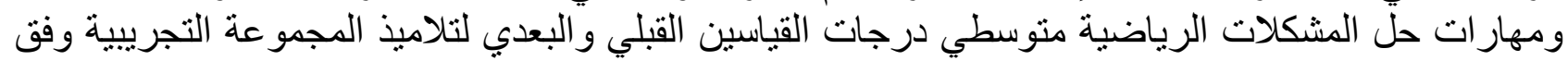

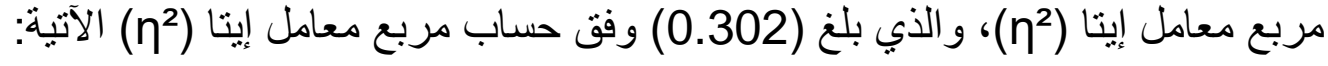
- قيمة مربع إيتا ( $\left(\left(152+(-4.106)^{2}\right) \quad /(-8.106)^{2}=\left(\eta^{2}\right)\right.$ - قيمة مربع إيتا $0.302=\left(\eta^{2}\right)$ - قيمة مربع إيتا

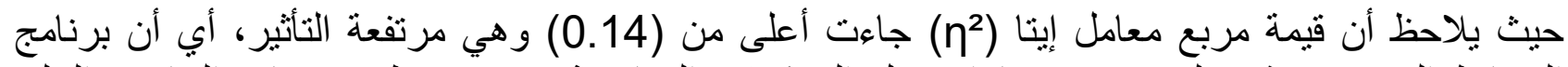

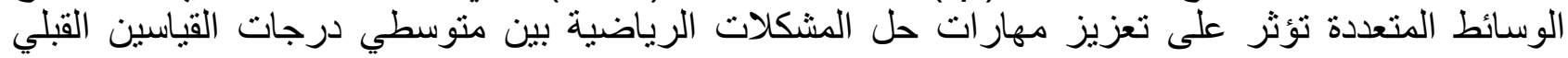

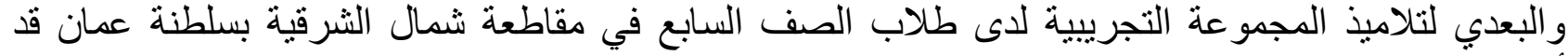
أسهمت ما مقداره (30.2\%) من مستوى مهارات حل المشكلات الرئي الرياضية للمجموعة البعدية في مادة الرياضيات.

إن ارتفاع متوسط دراجات الطلاب المقياس البعدي مقارنة بمتوسط درجات الطلاب في المقياس القبلي لتلاميذ

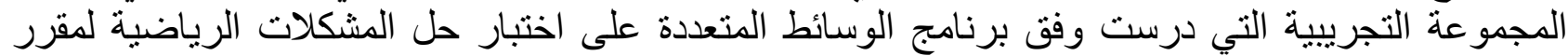

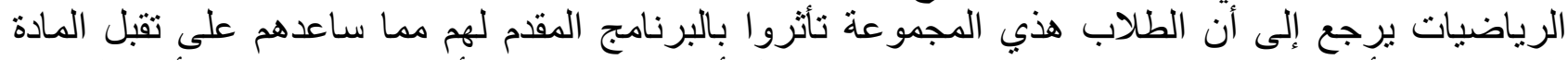

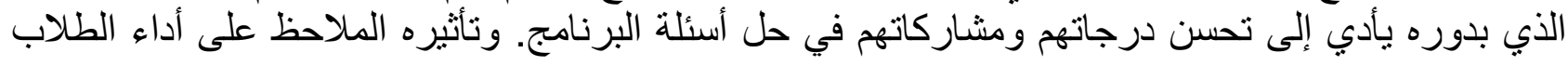




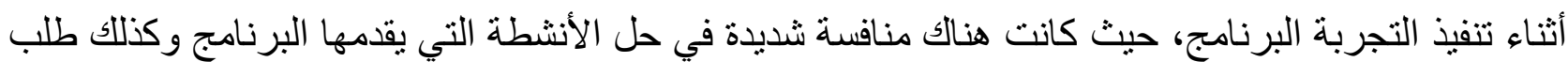

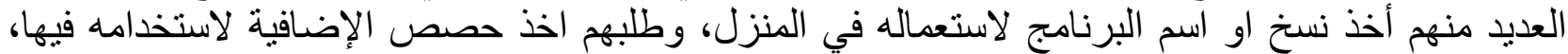

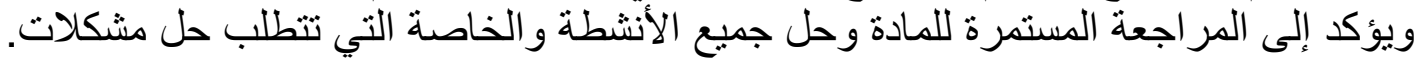
و هذه النتائج تتفق مع العديد من الدراسات التي تم التطرق إليها البحاث في الإطار النظري ومنها: دراسة

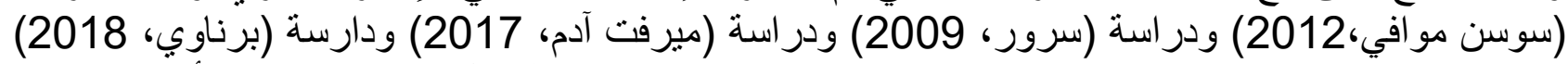

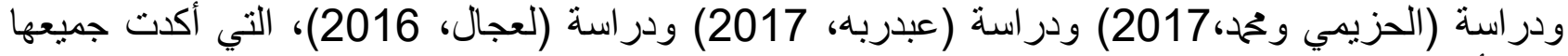
على أثر البرمجيات التعلمية في تحسن مستوى طلاب المجموعة التجريبية في الاختبار البعدي عن الاختبار

يظهر واضحا وجود فروق ذات دلالة إحصائية عند مستوى الدلالة (0.05) بين درجات مهارات حل

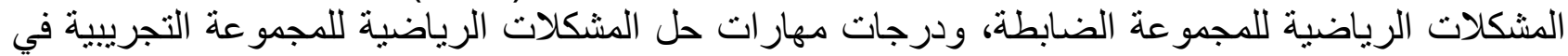

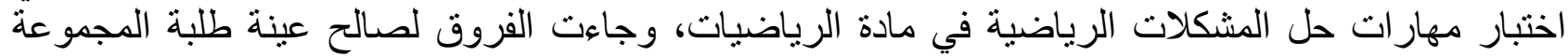

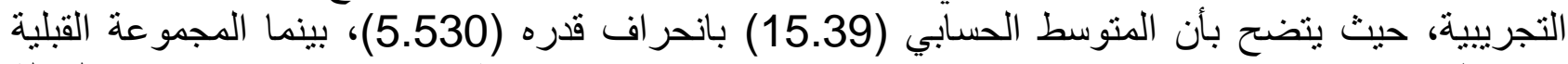
بمتوسط حسابي (10.91) وبانحراف معياري قدره (6.475) عند قيمة ت (4.61)) ومسنوى الدلالة . (0.00)

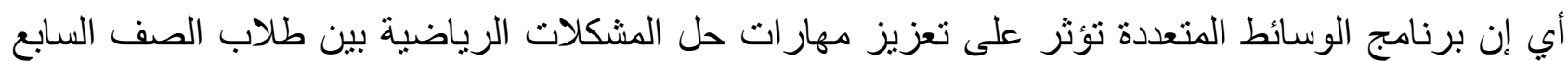

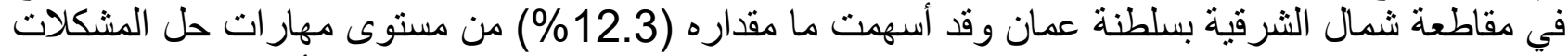

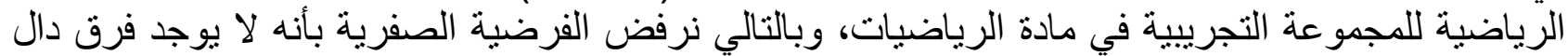

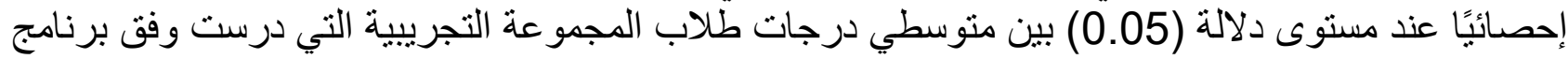
الوسائط المتعددة وطلاب المجموعة الضابطة التي درست بالطريقة التقليدية على اختبار حل المشكلات

الرياضية.

ويرجع هذا التقدم والتحسن في نتائج الطلاب في الاختبار البعدي الذي يقيس تعزيز مهار ات حل المشكلات

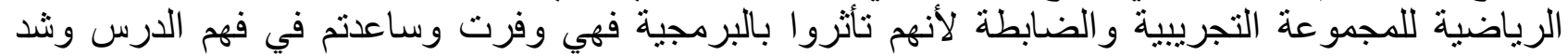

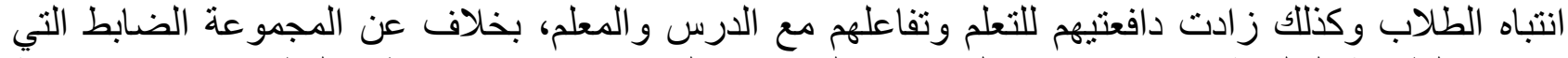

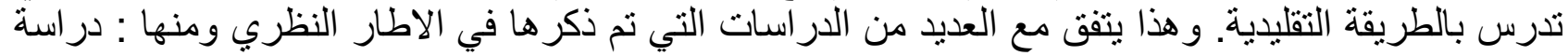

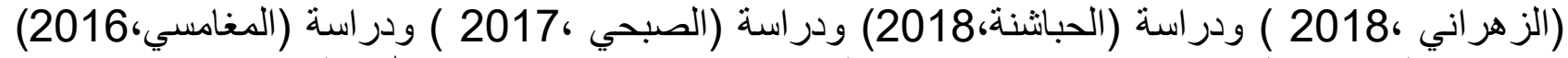
ودارسة (العايذي والرياشي، 20014) ودر اسة (القرني، 2013) ودارسة (عبدالله والشوا، 2011) ودردة ودردة استة

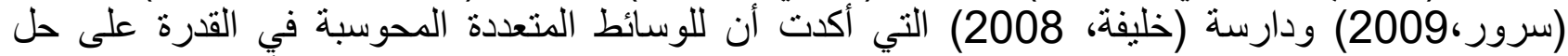

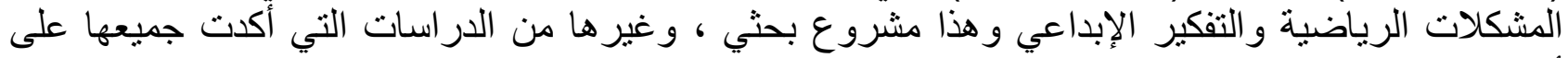

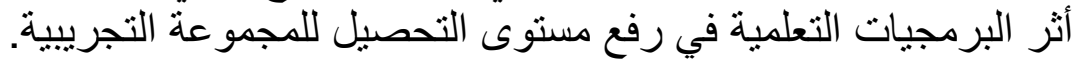

هذا يجرنا إلى حل أساس المشكلة التي تنطوي حولها الدراسة (تدني مستوى أداء طلاب الصف الدف السابع عند الدئ

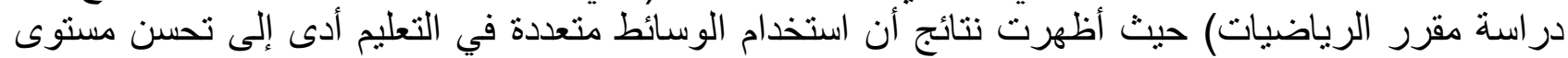
الطلاب في نتائج اختبار وهذا لم يحصل في المجمو عة الضابطة التي استخدمت الطريقة التقليدية في التدريس. يخلص الباحث من خلال ما سبق للإجابة عن السؤال الأول (ما مدى تأثير الوسائط المتعددة على تعزيز

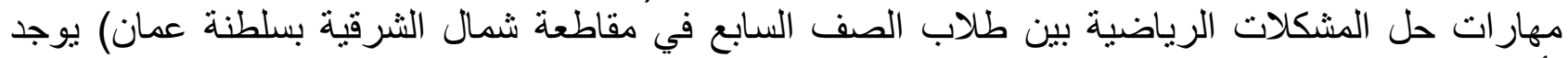

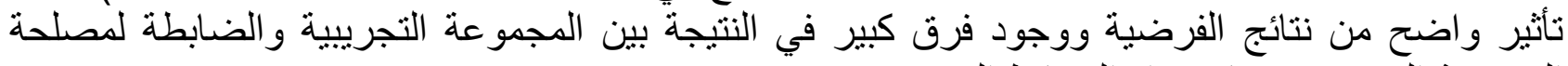
التجريبية التي درست باستخدام الوسائط المتعددة.

\section{عرض النتائج المتعلقة بالسؤال الثالث وتثفيرها:}

نص هذا السؤال على الاتي: ما مقترحات المعلمين والأخصائيين في تطوير برنامج الوسائط المتعددة في

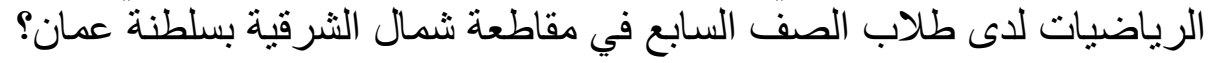


ولتفسير الإجابة عن السؤال الخامس (المفتوح) الموجه للطلاب و المعلمين والمختصين، في مجال التقنية

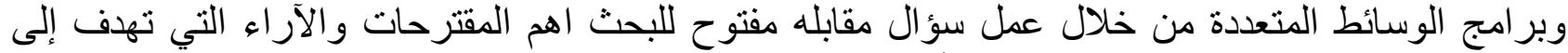

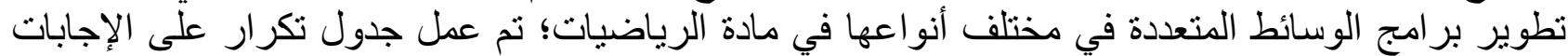

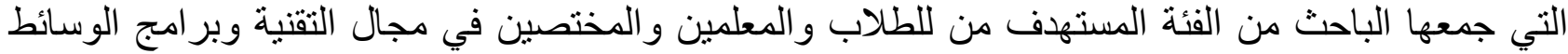

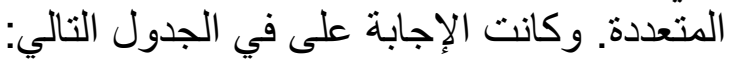

الجدول (5) يوضح تكر ار مقترحات المعلمين و الأخصائيين في تطوير برنامج الوسائط المتعددة في الرياضيات لاى طلاب الصف السابع في مقاطعة شمال الثرقية بسلطنة عمان.

\begin{tabular}{|c|c|c|}
\hline 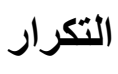 & 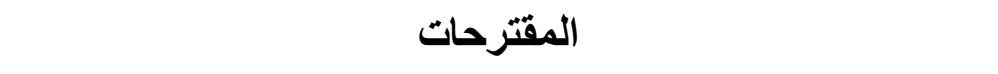 & b \\
\hline 5 & إنشاء تطبيقات تفاعلية تخدم مادة الرياضيات & 1 \\
\hline 3 & دروس مباشرة (أون لاين) & 2 \\
\hline 7 & توفير أدوات و أجهزه في كل قاعه & 3 \\
\hline 4 & تعميم هذه التجربة في المدارس (تبني وزارة التربية الفكرة) & 4 \\
\hline 5 & توفير شبكات إنترنت في كل قاعه تدريسية & 5 \\
\hline 3 & عمل إلعاب تعليمية في الرياضيات & 6 \\
\hline 3 & التنويع في بر امج التدريس لتحميس الطلاب على فهم الدرس & 7 \\
\hline 2 & في الرياضيات مشاغل وورش في كيفية استخدام برنامج الوسائط المتعددة & 8 \\
\hline 1 & إعداد دروس الكرنونية مساعده لتدريس الرياضيات & 9 \\
\hline 1 & توفير مختبر خاص لمادة الرياضيات مثل باقي مواد العلوم & 10 \\
\hline
\end{tabular}

يتبين من نتيجة السؤ ال الخامس والتي تم عرضها في الجدول السابق رقم (23) وكان عدد المستهدفين 34فرد

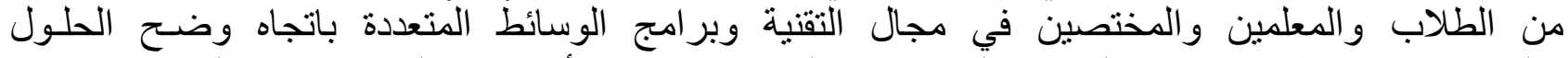
و المقترحات في تطوير برنامج الوسائط المتعددة في الرياضيات. ومن أبرز هذه المقترحات ما يلي: أ. إنثاء تطبيقات تفاعلية تخدم مادة الرياضيات ب. عمل دروس مباشرة (أون لاين) من خلال منصات تعلمية ت.توفير أدو ات و أجهزه في كل قاعه (مثل شاشات وحو اسيب وبركسيكما وسماعات ....) ث.تعميم هذه التجربة في المدارس (تبني وزارة التربية الفكرة) ج. توفير شبكات إنترنت في كل قاعه تدريسية ح. عمل إلعاب تعليمية في الرياضيات

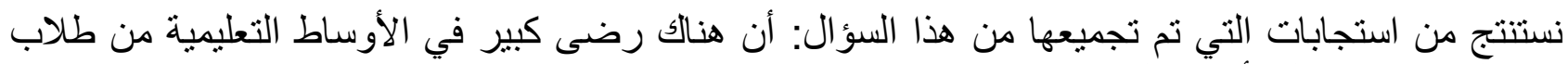
و المعلمين وفنيين إلى أهمية التعليم الإلكتروني واستخدام بر امج الوسائط المتعددة وتطبيقات في الهي الهو التف الف الذكية 
التي تجعل التعليم أفضل وأسهل وير اعي جميع المستويات والاتجاهات.

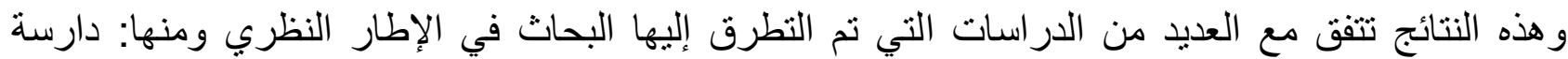

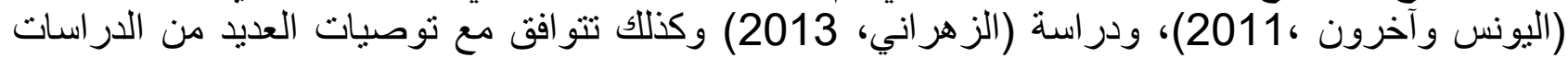

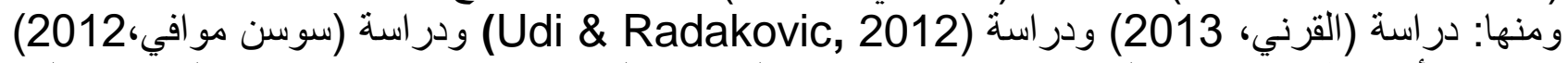

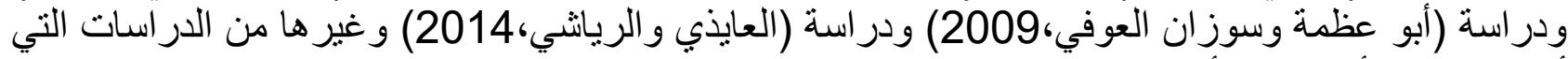
أكدت جميعها أو بعضها أنه لا بد من تطوير التعليم باستخدام والوسائط المتعددة.

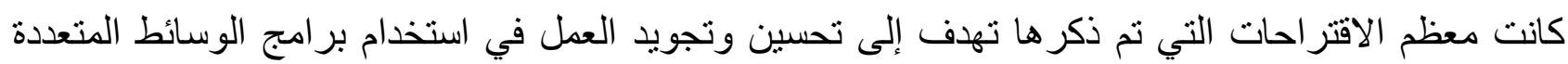

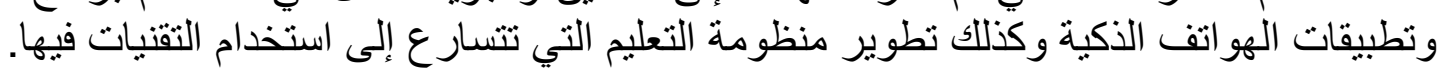

\section{قائمة المراجع:}

أبو زينة، فريد كامل و عبد الله يوسف عبابنة (2010)، مناهج تدريس الرياضيات للصفوف الأولى، ط2، دار

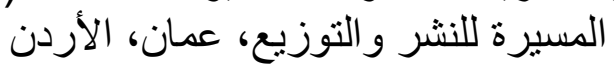

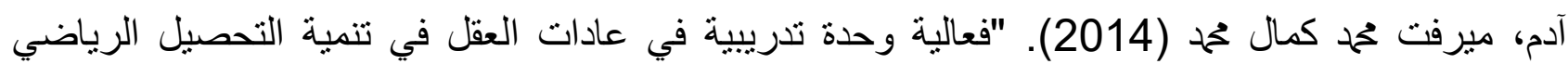

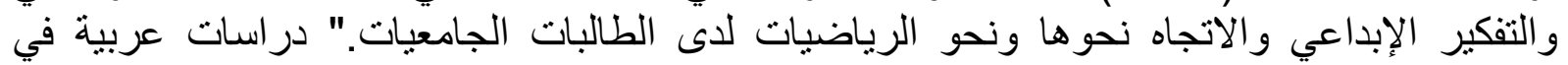

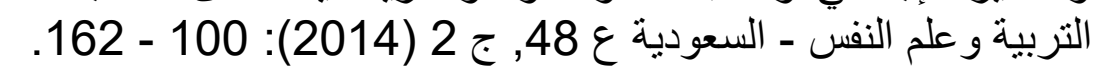

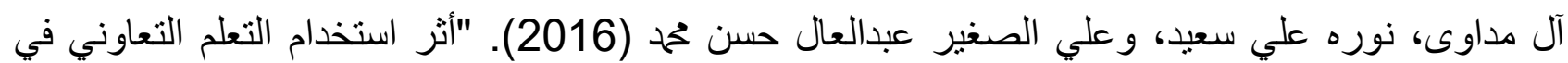

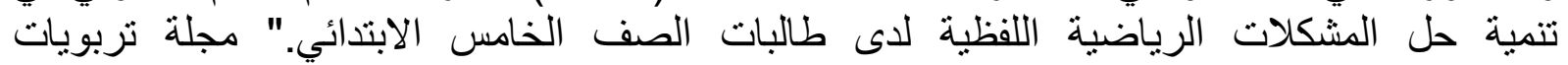

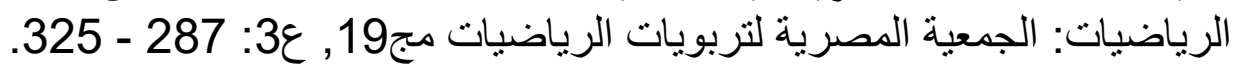

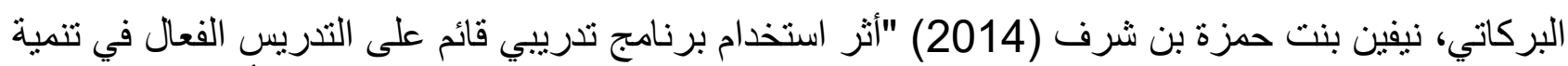

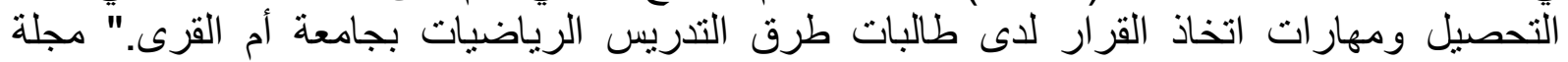

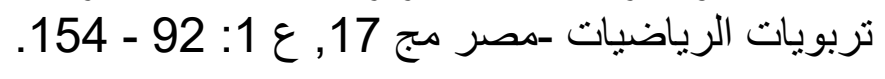

بيومي، ياسر عبد الرحيم، وحسن عوض حسن الجندي (2017). "فعالية استراتيجية عظم السمكة في تنمية الإنية

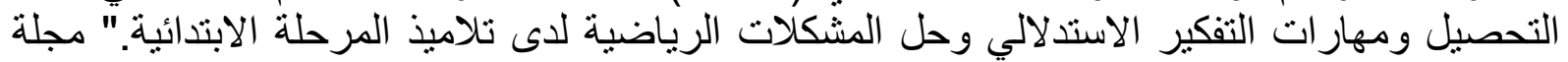

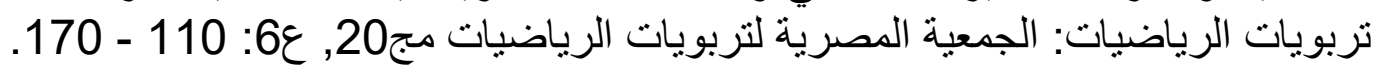

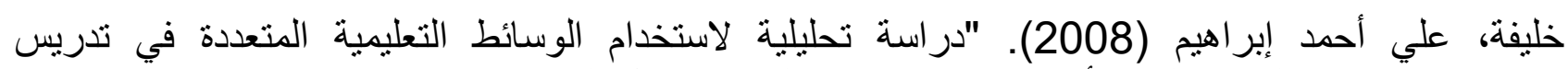

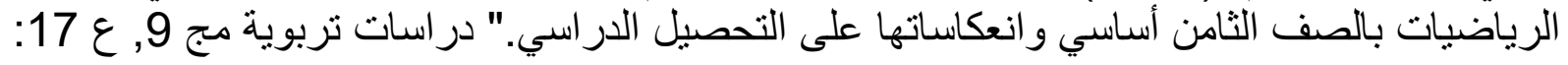

. 181 - 138

خميس، مححد عطية (2007). الكمبيوتر التعليمي وتكنولوجيا الوسائط المتعددة. القاهرة: مكتبة دار السحاب للنشر و التوزيع.

الراجح، نوال بنت محمد عبد الرحمن (2015). "مستوى حل المشكلات الرياضية لإى طالبات جامعة الأميرة

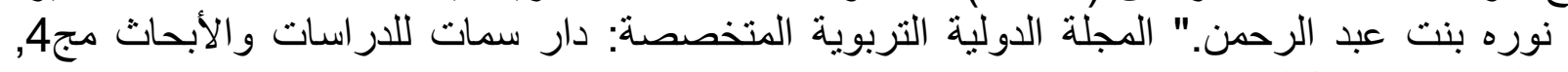

$$
216 \text { - } 200: 3 \varepsilon
$$

الثيخي، هاثم بن سعيد بن أحمد (2016). "مستوى القدرة على حل المشكلات الرياضية في فرعي الأعداد

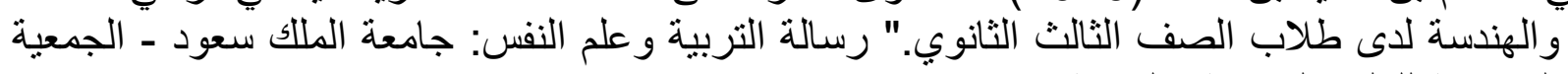

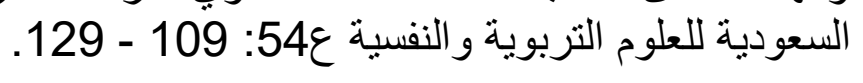

عبيد، وليم (1998). رياضيات مجتمعية لمواجهة تحديات مستقبلية (إطار مقترح لتطوير مناهج الرياضيات 
مع بداية القرن الحادي و العثرين). مجلة نربويات الرياضيات، الجمعية المصرية لتربويات الرياضيات،

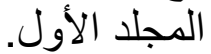

عزمي، نبيل جاد (2011)، التصميم التعليمي للوسائط المتعددة، ط 2، المنيا: دار الهدى للنشر والتوزيع. عسيرى، عبد الله على عبد الله آل عواض (2016). "أثر تدريس الرياضيات باستخدام إستراتيجية الجدول الذاتي في تحصيل طلاب الصف الخامس الابتدائي بمدارس خميس مشيط." الثقافة والتنمية ـمصر

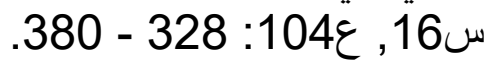

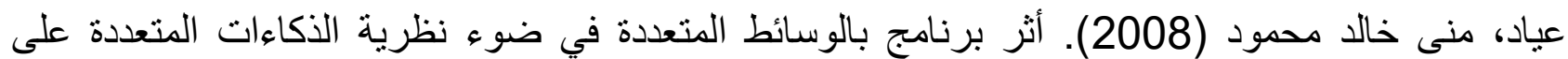

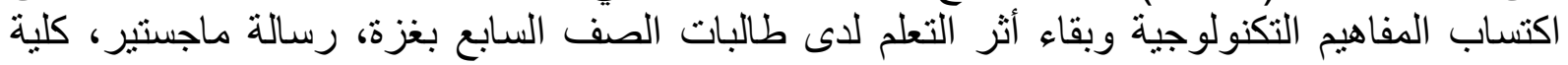
التربية، الجامعة الإسلامية بغزة المفابة

فتح الرحمن، عازة حسن، ومختار عثمان الصديق. (2010). "الإبداع في التدريس الجامعي باستخدام الوسائط

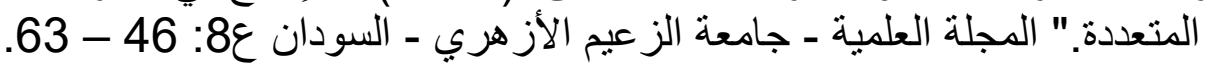

المالحي، هاني تحمد حامد (2006): فاعلية التدريس بالاكتشاف الموجه من خلال معمل الرياضيات في تنمية

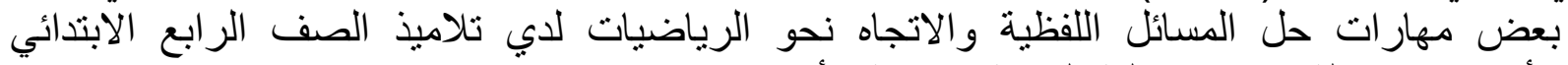

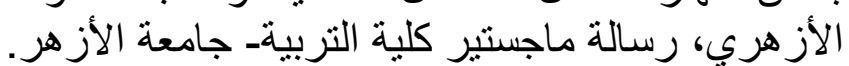

النجدي، أحمد عبد الرحمن (2015) المنهج في عصر ما بعد الحداثة، ط3، دار الأقصى للطباع، القاهرة. وزارة التربية والتعليم. (2018) التقرير الوطني للار اسة الدولية في الرياضيات و العلوم (TIMSS 2015). سلطنة عمان: المديرية العامة لتطوير المناهج.

\section{ARABIC REFERENCES IN ROMAN ALPHABET}

Abu Zinat, Farid Kamil Waeabd Allah Yusif Ebabn. (2010). Manahij Tadris Alriyadiat Lilsufuf Al'uwlaa, T2, Dar Almasirat Lilnashr Waltawziei, Eaman, Al'urdun

Adam, Mirafat Muhamad Kamal Muhamad (2014). "Fealiat Wahdat Tadribiat fi Eadat Aleaql fi Tanmiat Altahsil Alriyadii Waltafkir Al'iibdaeii Walaitijah Nahwaha Wanahw Alriyadiaat Ladaa Altaalibat Aljamieiaat." Dirasat Earabiat fi Altarbiat Waealam Alnafs - Alsewdyt E 48, J 2 (2014): 100 - 162.

Al Madawaa, Nurih Eali Saeayd, Waeali Alsaghir Eabdaleal Hasan Muhamad. (2016). "Athar Aistikhdam Altaealim Altaeawunii fi Tanmiat Hali Almushkilat Alriyadiat Allafaziat Ladaa Talibat Alsafi Alkhamis Alaibtidayiy." Majalat Tarbawiat Alriyadiat: Aljameiat Almisriat Litarbuiat Alriyadiaat Mj19, E3: 287 325.

Alburkati, Nyfyn Bnt Hamzatan Bin Sharaf. (2014). "lathar Aistikhdam Barnamaj Tadribiin Qayim Ealaa Altadris Alfaeeal fi Tanmiat Altahsil Wamaharat Aitikhadh Alqarar Ladaa Talibat Turuq Altadris Alriyadiat Bijamieat 'Ama Alquraa." Majalat Tarbawiat Alriyadiat -Msr Maj 17, E 1: 92 - 154.

Biumi, Yasir Eabd Alrahim, Wahusn Eiwad Hasan Aljundayi. (2017). "Fealiatan 'listratijiatan Eazm Alsamakat fi Tanmiat Altahsil Wamaharat Altafkir Alaistidlalii Wahali Almushkilat Alriyadiat Ladaa Talamidh Almarhalat Alaibtidayiya." Majalat Tarbawiat Alriyadiat: Aljameiat Almisriat Litarbuiat Alriyadiaat Mj20, E6: 110 - 170.

Khalifat, Eali 'Ahmad 'librahim. (2008). "Drast Tahliliatan Liaistikhdam Alwasayit Altaelimiat Almutaeadidat fi Tadris Alriyadiat Bialsafi Alththamin 'Asasia Waineikasatiha Ealaa Altahsil Aldarasi." Dirasat Tarbawiat Maj 9, E 17: 138 - 181.

Khamis, Muhamad Eatia. (2007). Alkimbiutir Altaelimiu Watiknulujia Alwasayit Almutaeadidata. Alqahrt: Maktabat Dar Alsahab Lilnashr Waltawzie.

Alrrajihu, Nuwwal Bnt Muhamad Eabd Alrhmn. (2015). "Mstwa Hala Almushkilat Alriyadiat Ladaa Talibat Jamieat Al'amirat Nurih Bnt Eabd Alrahmn." Almajalat Alduwaliat Altarbawiat Almtkhsst: Dar Simat Lildirasat Wal'abhath Mj4, E3: 200 - 216.

Alshaykhiu, Hashim Bin Saeid Bin 'Ahmad. (2016).. "Mstawaa Alqudrat Ealaa Hali Almushkilat Alriyadiat fi 
Farei Al'aedad Walhindisat Ladaa Tullab Alsafi Alththalith Althaanui." Risalat Altarbiat Waealam Alnfs: Jamieat Almalik Sueud - Aljameiat Alsewdyt Lileulum Altarbawiat Walnafsiat Ea54: 109 - 129.

Eubayd, Wilyam. (1998). Riadiat Mujtamaeiat Limuajahat Tahadiyat Mustaqbalia ('Itar Muqtarah Litatwir Manahij Alriyadiaat Mae Bidayat Alqarn Alhadi Waleishrina). Majalat Tarbuiaat Alriyadiaati, Aljameiat Almisriat Litarbuiaat Alriyadiaati, Almujalid Al'awl.

Eazmi, Nabil Jad. (2011). Altasmim Altaelimia Lilwasayit Almutaeadidat, T 2, Almnya: Dar Alhudaa Lilnashr Waltawzie.

Easayraa, Eabd Allah Ealaa Eabd Allah Al Eawwad. (2016). "Athur Tadris Alriyadiaat Biastikhdam 'listratijiat Aljadwal Aldhdhatii fi Tahsil Tullab Alsafi Alkhamis Alaibtidayiyi Bimadaris Khamis Mashit." Althaqafat Waltanmiat -Msur Sa16, Ea104: 328 - 380.

Eiadi, Munaa Khalid Mahmud. (2008). 'Athar Barnamaj Bialwasayit Almutaeadidat Fi Daw' Nazariat Aldhikaa'at Almutaeadidat Ealaa Aiktisab Almafahim Altiknulujiat Wabiqa' 'Athar Altaelum Ladaa Talibat Alsafi Alssabie Bighizati, Risalat Majstir, Kuliyat Altarbiati, Aljamieat Al'iislamiat Bighazat.

Fath Alrhmn, Eazat Hsn, Wamukhtar Euthman Alsadiqi. (2010). "Al'iibdae Fi Altadris Aljamieii Biastikhdam Alwasayit Almutaeadidati." Almajalat Aleilmiat - Jamieat Alzaeim Al'azhari - Alsuwdan E8: 46 - 63.

Almalhi, Hani Muhamad Hamid. (2006). Faeiliat Altadris Bialaiktishaf Almuajah min Khilal Maemal Alriyadiaat fi Tanmiat Bed Maharat Hali Almasayil Allafaziat Walaitijah Nahw Alriyadiaat Ladayi Talamidh Alsaf Alrrabie Alaibtidayiyi Al'azharii, Risalat Majstayr Kuliyat Altarbiati- Jamieat Al'azhr.

Alnajdi, 'Ahmad Eabd Alrihmn. (2015) Almunahj fi Easr Ma Baed Alhadathat, Ta3, Dar Al'aqsaa Liltibae, Alqahirat.

Wizarat Altarbiat Waltaelim. (2018) Altaqrir Alwataniu Lildirasat Alduwaliat Fi Alriyadiat Waleulum (2015 Timss). Saltanat Eimaana: Almudiriat Aleamat Litatwir Almunahij.

\section{REFERENCES}

Chung, I. (2004). A comparative assessment of constructivist and traditionalist approaches to establishing mathematical connections in learning multiplication education. Dissertation abstract International

National Council of Teachers of Mathematics (2003), Principals and Standards for School Mathematics, Reston, NTCM

Thomas K.F. Chiu, Ida A.C. Mock (2017) Learner expertise and mathematics different order thinking skills in multimedia learning, Computers \& Education, Vol 107, Pages 147-164. 